\title{
Novel popout and familiar popout in a brightness discrimination task
}

\author{
KRISTEN A. DILIBERTO, JEANETTE ALTARRIBA, and W. TRAMMELL NEILL \\ University at Albany, State University of New York, Albany, New York
}

\begin{abstract}
A single novel word among several familiarized words may be localized more effectively than the familiarized words (novel popout). Early demonstrations of novel popout attributed the effect to the capture of attentional resources by novel stimuli. Christie and Klein $(1995,1996)$ argued that differential recollection of novel versus familiar words could alternatively account for the popout effect. In the present experiments, participants judged which of four locations contained a physically brighter word. A bright novel word was localized significantly better than a bright familiar word in one-novel/threefamiliar arrays, inconsistent with a retrievability account of novel popout. However, a bright familiar word was also localized better than a bright novel word in three-novel/one-familiar arrays, inconsistent with the mismatch theory proposed by Johnston and Hawley (1994). The results suggest that familiarity and novelty provide a perceptual segregation of the odd item; superior brightness discrimination at that location may be due either to attentional capture or to locational ambiguity within the larger group.
\end{abstract}

Properties that distinguish one object from an array of others, such as luminance, color, or abrupt onset, may capture attention in a stimulus-driven fashion-that is, independent of a person's strategies or intentions (Theeuwes, 1991, 1992; Yantis \& Jonides, 1984; but see Jonides \& Yantis, 1988). Research by Johnston and colleagues (Hawley, Johnston, \& Farnham, 1994; Johnston, Hawley, \& Farnham, 1993; Johnston, Hawley, Plewe, Elliott, \& DeWitt, 1990) suggested that the novelty of an object may similarly capture attention, causing it to perceptually pop out against an array of familiarized items.

The novel popout effect has typically been demonstrated in a task in which participants are shown an array of four different words followed by a single probe word; they then attempt to indicate the initial location of the probed word. Some of the words are familiar in the context of the experiment because they appear repeatedly across trials; other words are novel, appearing only once. If an array contains three familiar words and one novel word, localization of the novel word is likely to be enhanced relative to an all-novel array (between-arrays novel popout), and localization of a familiar word may suffer relative to an all-familiar array (familiar sink-in). In some experiments, the novel word in a one-novel array is localized better than the familiar words in that array (withinarray novel popout), despite higher performance on allfamiliar arrays than on all-novel arrays (baseline effect).

This work was funded by a Faculty Research Grant awarded to the second author. We thank Molly Brown, Michelle Gruhn, Lauren May, and Tammy Schillinger for their assistance with data collection. We are also indebted to Ray Klein, Bradley Gibson, William Johnston, and Jan Theeuwes for helpful suggestions and comments on earlier versions of this manuscript. K. A. Diliberto is now at Berry College, Mount Berry, GA. Correspondence concerning this article can be addressed to J. Altarriba, Department of Psychology, University at Albany, State University of New York, Albany, NY 12222 (e-mail: ja087@csc. albany.edu).
Christie and Klein (1996) have raised questions regarding the theoretical interpretation of novel popout. They argued that the effects can be explained without reference to attentional capture and suggested alternative explanations for the results of Johnston and colleagues. Christie and Klein (1996) first noted that the betweenarrays novel-popout and familiar sink-in effects can be explained by overall processing load. A novel word may be processed more easily in a one-novel array than in an all-novel array simply because the overall processing load is less for the one-novel array. Similarly, processing a familiar item may be more difficult in a one-novel array than in an all-familiar array because the overall processing load is least in an all-familiar array. Therefore, only withinarray popout constitutes valid evidence of a processing advantage for novel versus familiar stimuli. However, in the experiments that initially demonstrated a statistically significant within-array effect, the novel words were probed in half of the one-novel arrays - that is, twice as often as would be expected by chance. Participants may therefore have been biased to preferentially encode the location of the novel word.

More recent research (Diliberto, Altarriba, \& Neill, 1998, Experiment 1; Johnston \& Schwarting, 1997, Experiment 2) has obtained statistically reliable withinarray novel popout under conditions that satisfy this criticism by Christie and Klein (1996)-specifically, by probing the location of the novel word at chance $(25 \%)$ in the one-novel displays. However, confirmation of this effect may not be sufficient to infer that the effect is due to orienting of attention. Christie and Klein (1996) also noted that the word-localization task requires retrieval of identity information from memory when the probe word is presented. It is therefore ambiguous as to whether superior performance on the novel word is caused by attentional orienting during the display or by an advantage in 
memory retrieval. Christie and Klein argued that attentional orienting must be inferred from judgments of some attribute that is independent of the word's identity. For example, Christie and Klein (1995) found that participants detected the motion of a familiar word more accurately than that of a novel word in two-item displays. ${ }^{1}$

The present experiments required participants to judge which of four locations contained a brighter word, relative to the other three words. Because brightness localization does not require reference to the word identity, differential recollection of novel versus familiar words could not account for superior performance on novelword targets. Hence, novel popout in these experiments would imply a perceptual locus of the effect- that is, preferential encoding of information at the novel-stimulus location during perception of the stimulus array.

\section{EXPERIMENT 1}

\section{Method}

Participants. Forty-two undergraduate students enrolled in lower level undergraduate psychology courses at the University at Albany, State University of New York, participated to satisfy a course requirement or to receive extra credit toward the course grade. Each participant was a native speaker of American English and had normal or corrected-to-normal vision. Each participant was tested individually in a session of approximately $20 \mathrm{~min}$.

Materials and Apparatus. The stimuli were 175 singular nouns, four letters in length and with a Kučera-Francis (1967) frequency range of $1-424$ per million. Fifteen of these were randomly selected to serve as familiar words. The remaining 160 words served as novel words. The 15 familiar words were assigned to five sets of 3 words a piece. Each set of 3 familiar words appeared in 32 different arrays, paired each time with a different novel word, for a total of 160 experimental arrays. Forty practice arrays were generated, using the same sets of familiar words and 40 additional novel words from a separate pool.

All the experiments were presented on a Crystal Scan monitor interfaced with a Gateway $386 \mathrm{SX} / 25$ PC-compatible computer. The participants registered their responses on the keys of the numeric keypad on the computer keyboard. The program for the experiment was created by using Micro Experimental Laboratories (MEL) psychology software (Schneider, 1988, 1990).

Procedure. Each participant received 40 practice trials and 160 experimental trials. An array of four white rectangular boxes, arranged in the form of a horizontally elongated cross, was centered in the monitor at all times (similar to the procedure used by Johnston et al., 1993). The sequence of events on each trial is displayed in Figure 1. First, the participants were presented with a ready signal of four asterisks in each rectangular box for $200 \mathrm{msec}$ (Figure la). After an interstimulus interval (ISI) of $500 \mathrm{msec}$, four words (three familiar, one novel) appeared, each centered in a box in lowercase letters, for $200 \mathrm{msec}$ (Figure 1b). One of the four words, randomly selected, was made brighter by varying the intensity level for each of the color phosphors (red, green, blue), using the MEL color palette [i.e., $(63,63,63)]$. Following a 16-msec ISI, a mask of four uppercase Xs appeared in each location of the rectangle for $100 \mathrm{msec}$ (Figure 1c). Immediately following the mask, the screen cleared, and the participants were asked to indicate the location of the brighter word from the previous display (Figure 1d).

The participants used the numeric keypad located to the right of the computer keyboard for their responses. The spatial configuration of the keys corresponded to the locations of the words in the rectangular boxes. The participants were instructed to respond accurately and were told that speed was not important. In order to en- courage accuracy, the computer emitted a 500 -msec tone as feedback when an incorrect response was made. A blank intertrial interval of $500 \mathrm{msec}$ followed the participant's response before the next trial began. The participants were given a break after every 40 trials.

Each participant received a different random order of arrays. Each set of four words was randomly assigned to the four locations of the display, and each location was probed with equal frequency. Consequently, familiar words were probed on $75 \%$ of the trials, and novel words were probed on $25 \%$ of the trials.

\section{Results and Discussion}

The participants localized the brighter word more accurately when it was the novel word (mean proportion = .821) than when it was one of the familiar words [.799; $t(41)=2.25, p<.05$, two-tailed]. Thus, a within-array novel-popout effect can be obtained in a task that does not require a retrospective retrieval of the word identity. This implies that the effect must be due to preferential processing at the novel-word location during perception of the array, as would be predicted by attentional capture.

Although the brightness target was the novel word only at chance $(25 \%)$, it remains possible that the participants were biased to guess that the novel word's location contained the brighter stimulus. Accordingly, we examined the proportion of errors on familiar-word trials in which participants guessed the novel-word location. A binomial test indicated that the observed proportion (.296) was significantly less than the proportion expected by chance (.333; $p<.02$, two-tailed). Clearly participants were not biased toward guessing the novel-word location; indeed, they appear to be biased against such guesses.

\section{EXPERIMENT 2}

Because the magnitude of the novel-popout effect in Experiment 1 was small, a second experiment was conducted, both to replicate the effect and to test an alternative explanation for the effect. It is possible that the novel word was subjectively perceived as brighter than the familiar words, independent of actual brightness. Mandler, Nakamura, and Van Zandt (1987) found that participants judged previously exposed patterns to be brighter than new patterns. Mandler et al. argued that participants may misattribute brightness or other perceptual qualities to more perceptually fluent stimuli. Although it is a novel stimulus, rather than a familiarized one, that is presumed to be processed more fluently in the present experimental paradigm, participants might make a similar misattribution. To test this possibility, a quarter of the trials in Experiment 2 were catch trials, in which the four words were equiluminant. If the novel-popout effect here is due to greater subjective brightness of novel words, their locations should be selected on a greater than chance proportion $(25 \%)$ of the catch trials.

\section{Method}

Participants. Forty-nine undergraduate students enrolled in lower level undergraduate psychology courses at the University at Albany, State University of New York, participated to satisfy a course 


\section{a. WARNING ARRAY $200 \mathrm{~ms}$}

\section{b. ATTENTION ARRAY $200 \mathrm{~ms}$}

\section{c. MASK $100 \mathrm{~ms}$}

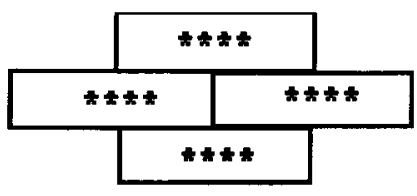

ISI $\mathbf{5 0 0 ~} \mathrm{ms}$

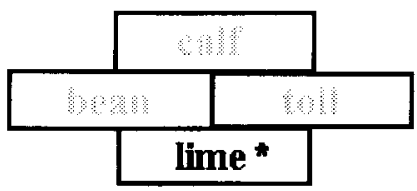

ISI $16 \mathrm{~ms}$

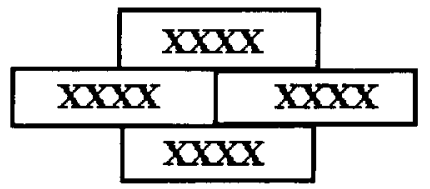

d.

Where was the brighter word?

\section{ITI 500 ms}

Figure 1. Example of the procedure for the trials in Experiments 1, 2,3, and 4. (Bold lettering represents a brighter word.)

requirement or to receive extra credit toward the course grade. None had participated in Experiment 1. All were native speakers of American English and had normal or corrected-to-normal vision.

Materials and Apparatus. The materials and apparatus were identical to those in Experiment 1.

Procedure. The procedure was identical to that in Experiment 1, except that 40 experimental arrays and 10 practice arrays were randomly selected for catch trials. On such trials, a target word was selected but not actually displayed in greater luminance than were the other three words. The participants were not informed about the catch trials. To maintain plausibility of feedback, feedback on catch trials was determined by whether the response corresponded to the selected target word.

\section{Results and Discussion}

On trials that actually contained a brighter target, the participants again localized the target more accurately if it was a novel word (.846) than if it was familiar [.821; $t(48)=2.29, p<.05$, two-tailed], replicating the withinarray novel-popout effect found in Experiment 1. The proportion of errors on familiar-target trials that were guesses of the novel-word location (.333) did not differ from chance (.333). Again, there is no indication that the participants were biased to guess that the novel word was brighter. The failure to replicate the opposite bias found in Experiment 1 may be due to a smaller number of error trials available for this analysis (759 trials, vs. 1,092 in Experiment 2).

The participants selected the novel-word location on $22.9 \%$ of the catch trials, significantly less than chance $[25 \% ; t(48)=2.58, p<.05$, two-tailed]. Thus, there is no evidence that novel words are subjectively brighter as a result of greater perceptual fluency. This result is also consistent with the analysis of errors on familiar-target trials in Experiment 1, again suggesting that the participants may have actually been biased against selecting the novel-word location.

\section{EXPERIMENT 3}

The results of the first two experiments clearly indicate that a within-array novel-popout effect can be ob- 
tained in a task that does not explicitly require recollection of the target word. However, the results do not distinguish between a localization superiority that is due to novelty per se and location superiority for a target that uniquely differs from the rest of the array in familiarity. A number of studies of visual search have found that targets are identified especially quickly if they are distinguished by a simple physical feature from the distractors in an array. Furthermore, a distractor that uniquely differs from other array items may interfere with locating a target, particularly if the participant is searching for a target also defined by a unique feature - that is, a singleton search (Bacon \& Egeth, 1994; Folk, Remington, \& Johnston, 1992; Folk, Remington, \& Wright, 1994; Theeuwes \& Burger, 1998). It is possible that familiarity may serve to segregate a unique item from other items in the array in a similar fashion. If so, a single familiar target imbedded in an array of other novel items should evince a similar superiority.

\section{Method}

Participants. Forty-four undergraduate students enrolled in lower level undergraduate psychology courses at the University at Albany, State University of New York, participated to receive extra credit toward their course grade. Each participant was a native speaker of American English and had normal or corrected-to-normal vision. The participants were tested in pairs in a session that lasted approximately $20 \mathrm{~min}$.

Materials and Apparatus. The apparatus was identical to that in Experiment 1. The same 15 familiar words from Experiment 1 were used to create the one-familiar arrays. Five words were added in order to create a total of 20 familiar words. In addition to the 160 novel words selected for Experiment 1, 320 novel words were added. To create the three-novel, one-familiar sets, each familiar word was grouped with 3 unique novel words. Each familiar word appeared eight times across the experiment, for a total of 160 experimental arrays. Forty practice arrays were generated, using the 20 familiar words and additional novel words from Experiment 3 not used in the experimental trials.

Procedure. The procedure was identical to that in Experiment 1, except that familiar words were now probed on $25 \%$ of the trials and novel words were probed on $75 \%$ of the trials. In addition, the word ERROR appeared in red uppercase letters, in place of a tone, as feedback.

\section{Results and Discussion}

Brightness localization was significantly better for the singleton familiar target $(.834)$ than for novel targets [.817; $t(43)=2.072, p<.05]$. Thus, a within-array familiarpopout effect occurs when a familiar target is a singleton against a background of novel items. Although the effect is small, it is comparable with the advantage of a novel singleton over familiar targets in Experiments 1 and 2. Furthermore, it may be noted that the manipulation of familiarity was necessarily weaker here than in the first two experiments: Whereas each familiar word was presented 40 times in the earlier experiments ( 32 experimental trials +8 practice trials), each familiar word was presented here only 10 times ( 8 experimental trials +2 practice trials).
As in the previous experiments, we tested whether the singleton advantage was due to a guessing bias by examing errors on nonsingleton targets: On trials in which the participants failed to correctly localize a novel-word target, the probability of guessing the familiar-word location was .332 , statistically equal to chance. Thus, the advantage of familiar targets in three-novel/one-familiar arrays is not easily attributable to a guessing bias.

Johnston et al. (1990, Experiments 1 and 3) failed to obtain a significant familiar-popout effect in experiments using the probe word technique, although a small nonsignificant advantage was obtained for familiar targets over novel targets in three-novel/one-familiar arrays. In both experiments, trials with three-novel/one-familiar arrays were randomly intermixed with other array compositions, including one-novel/three-familiar arrays. The magnitude of the within-array novel-popout effect in onenovel/three-familiar arrays was noticeably greater than the familiar-popout effect in three-novel/one-familiar arrays, in contrast to the similar magnitude of effects (approximately $2 \%$ ) between the present Experiment 3 and our previous experiments. On the other hand, the withinarray novel-popout effect achieved statistical significance in only one of the two experiments by Johnston et al. (1990) that also tested for a familiar-popout effect. As was noted by both Johnston et al. and Christie and Klein (1996), both experiments potentially biased participants to search for novel targets. Therefore, it is unclear whether the discrepancy between the present results and those of Johnston et al. (1990) is due to statistical power, design flaws in the latter, differences in task demands, or other factors.

\section{EXPERIMENT 4}

As was discussed in the introduction, Christie and Klein (1996) criticized between-array comparisons (e.g., novel targets in one-novel/three-familiar arrays vs. allnovel arrays) as potentially contaminated by differences in processing demands of the whole arrays. In their defense, Johnston and Schwarting (1996) argued that exclusive reliance on within-array comparisons might be unreasonably stringent owing to the baseline effect - that is, an intrinsic encoding advantage for familiar words over novel words, independent of the context in which they are embedded. Indeed, such a baseline effect is manifested in superior localization of word targets in allfamiliar arrays relative to all-novel arrays (e.g., Johnston et al., 1990, Experiment 4).

A baseline effect would not only work against obtaining a reliable within-array novel-popout effect in onenovel/three-familiar arrays, it would bias results toward a familiar-popout effect in three-novel/one-familiar arrays. It is obvious that easier encoding of familiar words would contribute to performance in a task that explicitly requires recollection of such words, as in the probe word procedure used by Johnston et al. (1990). It is less obvi- 
ous that easier encoding of word identity should confer an advantage for localizing a brightness differential. Nonetheless, a baseline effect cannot be logically excluded. Therefore, Experiment 4 directly tested for a baseline effect in the brightness detection task by comparing all-familiar and all-novel arrays. Because interpretation of a null result would be especially problematic in the context of the small effect obtained in Experiment 3, we attempted to increase the strength of the familiarity manipulation by doubling the number of exposures of each familiar word ( 16 experimental +4 practice).

\section{Method}

Participants. Forty-four undergraduate students enrolled in lower level undergraduate psychology courses at the University at Albany, State University of New York, participated to receive extra credit toward their course grade. Each participant was a native speaker of American English and had normal or corrected-to-normal vision. The participants were tested in pairs in a session that lasted approximately $20 \mathrm{~min}$.

Materials and Apparatus. The apparatus was identical to that in the previous experiments. The same 20 familiar words from Experiment 3 were used to create the all-familiar sets. The words were divided into five sets of four familiar words. Three of the familiar words in each set of four words were identical to the triplets used in Experiment 1. Each set of four familiar words appeared 16 times across the experiment, for a total of 80 all-familiar arrays. Three hundred twenty of the novel words from Experiment 3 were used to create 80 all-novel arrays. Thus, the participants were presented with a total of 160 experimental arrays ( 80 all-familiar, 80 all-novel).

Forty practice arrays ( 20 all-familiar, 20 all-novel) were generated, using the same sets of familiar words and 80 additional novel words taken from Experiment 3. Each set of familiar words appeared four times.

Procedure. The procedure was identical to that in Experiment 3, except that familiar words were now probed on $50 \%$ of the trials and novel words were probed on $50 \%$ of the trials.

\section{Results and Discussion}

Localization of the brightness target was virtually identical in the all-familiar and all-novel arrays ( .875 and .872 , respectively), despite a stronger manipulation of familiarity than in Experiment 3. Thus, there does not appear to be an intrinsic advantage to brightness discrimination for familiarized words. Although caution is always warranted in interpreting a null result, the results suggest that the advantage for a familiar singleton in Experiment 3 was not due to a baseline effect. Rather, it appears to reflect the contrast in familiarity relative to the background of other items in the array, just as a novel singleton contrasts with multiple familiarized items.

\section{GENERAL DISCUSSION}

The novel-popout effect, initially described by Johnston et al. (1990), has often been assumed to reflect a tendency of novel stimuli to capture attention. In many experiments on novel popout, participants have been required to report the location of a particular word, queried after the initial array presentation. As was argued by Christie and Klein $(1995,1996)$, this procedure allows the possibility that differential memorability, not attentional capture, can account for the advantage of novel targets. In order to demonstrate a true attentional capture, it would be necessary to demonstrate a novel-target advantage in a task that does not require recollection of the target identity. The present experiments satisfied this criterion by requiring report only of the location containing a greater brightness. Indeed, Experiments 1 and 2 did show an advantage for the novel word in an array with three familiarized words. However, in Experiment 3, a similar advantage occurred for a single familiarized word in an array with three novel words. Thus, on the assumption of no baseline effect (Experiment 4), it is not novelty that causes a processing advantage in the present task but, rather, uniqueness of level of familiarity.

The conclusion that novelty itself does not account for the novel-popout effect is consistent with the findings of Diliberto et al. (1998). Johnston et al. (1993, Experiment 4) had previously found a novel-popout effect only if sets of familiarized words were shown repeatedly in the same arrays. Thus, learned interitem associations for the familiarized items appeared to be critical to the effect. Diliberto et al. (1998, Experiment 2) demonstrated that interitem associations were in fact sufficient to cause a popout effect even when every word was displayed only once in the course of the experiment: In arrays of three categorically related words and one unrelated word (e.g., FIR, OAK, ELM, HAT), the unrelated word was localized more accurately. This occurred despite an advantage of all-related arrays over all-unrelated arrays - that is, a baseline effect (Diliberto et al., 1998, Experiment 3).

According to the mismatch theory proposed by Johnston and Hawley (1994), novel popout is caused by the top-down inhibition of low-level iconic nodes by higher level identity nodes (Figure 2). The identity nodes are assumed to be more highly activated for familiar and expected stimuli; they further activate each other through mutual excitatory connections learned during familiarization. However, the iconic nodes are presumed to laterally inhibit each other. Consequently, if familiar and novel stimuli are simultaneously present, the top-down inhibition of the iconic node for a familiar stimulus tends to disinhibit the iconic node for the unfamiliar stimulus, which in turn further inhibits the iconic node for the familiar stimulus. Hence, perceptual processing of the familiar stimulus is suppressed, and perceptual processing of the unfamiliar stimulus is enhanced.

Although the results of Diliberto et al. (1998) suggest that the interitem associations, not novelty per se, accounts for novel popout, those results are generally consistent with the mismatch theory proposed by Johnston and Hawley (1994). That is, without the mutual lateral excitation of the identity nodes, top-down inhibition of the iconic nodes might be insufficient to suppress perceptual processing of the familiar stimuli. On the other hand, the mismatch model does not provide any mechanism to account for familiar popout when a single familiar item is presented with multiple novel items. 


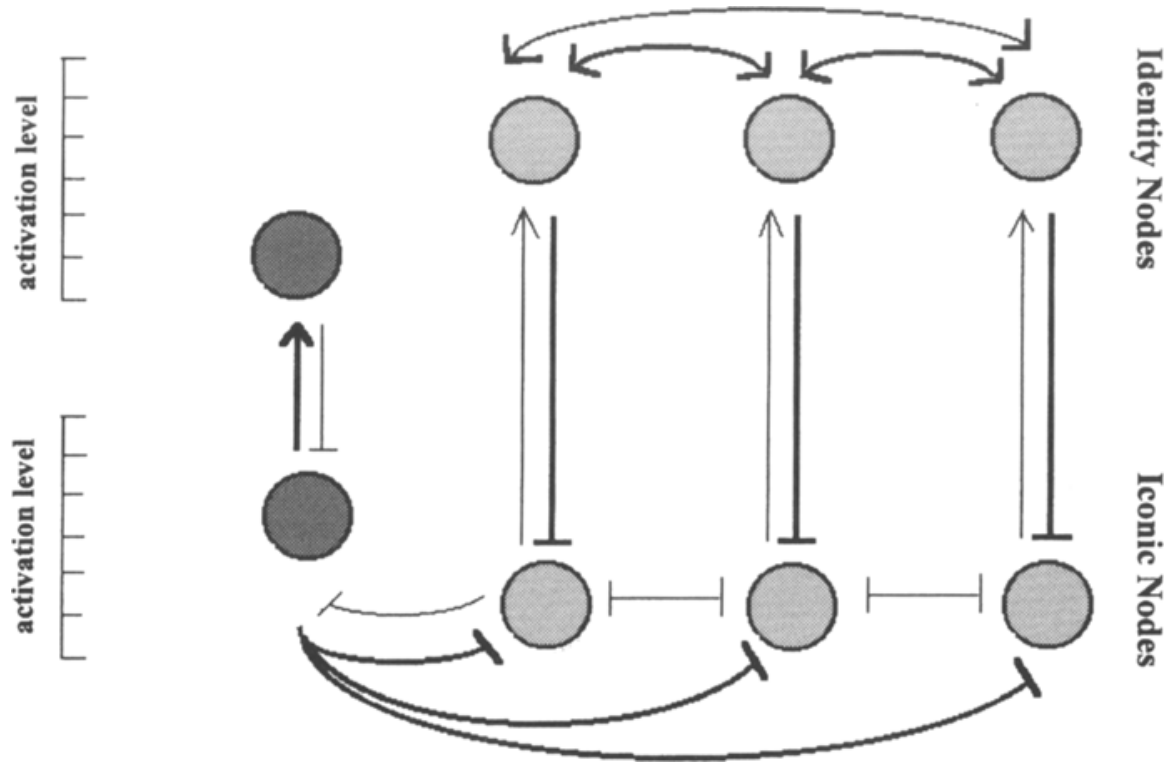

Figure 2. An illustration of the basic components of mismatch theory adapted from Johnston and Hawley (1994, p. 64). Lines terminating with arrows indicate excitatory connections, and those with bars indicate inhibitory connections. The strength of excitation or inhibition is indicated by the relative thickness of the lines. Note that for simplicity of presentation, we have omitted location nodes assumed to be associated with the iconic nodes.

The symmetry of results for novel singletons and familiar singletons in the present experiments suggests that level of familiarity may provide a basis for perceptual grouping in much the same way as color or shape. Thus, the odd item would be perceptually segregated from the items of common familiarity. Several possible mechanisms might account for superior localization of the brightness target when it coincides with the odd familiar or novel item in the array.

First, as was noted earlier, a nominally irrelevant singleton may tend to capture attention. There is debate on whether singletons can capture attention automatically, independent of participants' goals or strategies. However, attentional capture seems especially likely when the participant is engaged in a singleton search - that is, is searching for a target defined by a unique value on some dimension (Bacon \& Egeth, 1994; Folk et al., 1992; Folk et al., 1994; Theeuwes \& Burger, 1998). Thus, in the present experiments, an attentional set for a brightness singleton might leave the participant vulnerable to attentional capture by a familiarity singleton. A potential problem for this explanation is that participants can avoid attentional capture when the singleton values of the target and the distractor are both completely predictable (Theeuwes \& Burger, 1998). On the other hand, participants may not have consciously recognized novelty in Experiments 1 and 2 or familiarity in Experiment 3 as defining attributes of singleton distractors and so may have been unable to engage a strategy for ignoring the irrelevant singleton.

An alternative explanation, suggested to us by $\mathrm{R}$. Klein (personal communication, November, 1997), is that loca- tional uncertainty may be greater within a larger perceptual group. If the brightness target is detected to coincide with a familiar or novel singleton, there is no ambiguity of location. However, if the brightness target is detected in the larger perceptual group, there may be some ambiguity as to precisely where in that region it occurred. A related explanation is that perceived brightness may tend to be averaged over elements within a perceptual group. This would tend to dilute the perceived brightness of the target when it occurred in the larger group, in turn making its detection more difficult.

Experiment 1 found a small but significant bias against guessing the singleton location when participants made an error in localizing a brightness target among the nonsingletons. That is, they tended to guess one of the other two nonsingleton locations more frequently than chance. This result is consistent with all three explanations for the advantage of a brightness target's occurring in the singleton location. If a singleton tends to attract attention to its location, it should not only be easier to detect the brightness target when it is there, but also easier to reject that location when it is elsewhere. Guesses would therefore tend to be distributed among the other locations. Similarly, if a brightness increment is detected as having occurred somewhere in the larger perceptual group, guesses would tend to occur more often for those locations. Finally, if perceived brightness tends to be averaged over elements within a perceptual group, the two nontarget locations may tend to acquire some perceived brightness increment from the target stimulus in the same group. 
The analysis of catch trials in Experiment 2 tends, however, to favor the attentional capture explanation. That is, there was no actual brightness increment in the array. Therefore, locational uncertainty within the larger perceptual group would not by itself lead participants to mislocalize a perceived brightness increment within that group. Furthermore, any averaging of perceived brightness across the larger group would result in no difference from the singleton. On the other hand, attentional capture by the singleton accounts directly for this result, just as above: It should be easier to determine that the brightness target did not occur at that location, forcing guesses to be distributed more over the remaining locations.

The major conclusion of this study is that a difference in familiarity can segregate a unique item from other items in an array, with the consequence that processing of an independent perceptual attribute (brightness) is enhanced at that location. Because the effects appear to be symmetrical for novel singletons and familiar singletons, it does not appear that novelty per se confers a processing advantage, but rather the contrast in familiarity. As such, the results raise problems for the mismatch theory, proposed by Johnston and Hawley (1994) to specifically account for novel popout.

In fairness to the mismatch theory, it should be noted that the present procedures differ from most experiments designed to test novel popout. In such experiments (e.g., Diliberto et al., 1998; Johnston et al., 1993; Johnston et al., 1990; Johnston \& Schwarting, 1997), a probe word is typically displayed after termination of the stimulus array. Hence, there is no specific target during the array presentation, and participants are obliged to process all of the words as best they can. In contrast, in the present experiments, the target (greater brightness) was defined for participants well before each test array. As such, the present procedures are more consistent with those typically used to investigate visual search, and more specifically, they encourage participants to adopt a singleton search strategy. As was noted above, it has been suggested that irrelevant singletons are most likely to capture attention if participants have adopted an attentional set for a singleton target. Therefore, it is unclear whether the mechanisms operating in the present experiments would also operate in the typical experiments on novel popout.

At the same time, this ambiguity creates a double-bind for testing the mismatch theory and the more general proposition that novel stimuli capture attention. To extend the argument of Christie and Klein $(1995,1996)$, any procedure in which a target is defined only after the stimulus array will necessarily be vulnerable to effects of differential memorability. In order to obtain a more online measure of processing, it is necessary to define the critical target prior to (or perhaps simultaneously with) the stimulus array. To the best of our knowledge, no study has shown an inherent advantage for novel stimuli in such a procedure. Therefore, we must agree with Christie and Klein that the evidence for novel popout as an attentional effect is tenuous; or, to echo our previous conclusions
(Diliberto et al., 1998, p. 429), "novel popout does not depend on novelty."

\section{REFERENCES}

Bacon, W. F., \& EgETH, H. E. (1994). Overriding stimulus-driven attentional capture. Perception \& Psychophysics, 55, 485-496.

Christie, J., \& Klein, R. (1995). Familiarity and attention: Does what we know affect what we notice? Memory \& Cognition, 23, 547-550.

Christie, J., \& Klein, R. M. (1996). Assessing the evidence for novel popout. Journal of Experimental Psychology: General, 125, 201-207.

Diliberto, K. A., Altarriba, J., \& Neill, W. T. (1998). Novel popout without novelty. Memory \& Cognition, 26, 429-434.

Folk, C. L., Remington, R. W., \& Johnston, J. C. (1992). Involuntary covert orienting is contingent on attentional control settings. Journal of Experimental Psychology: Human Perception \& Performance, 18, 1030-1044.

Folk, C. L., Remington, R. W., \& Wright, J. H. (1994). The structure of attentional control: Contingent attentional capture by apparent motion, abrupt onset, and color. Journal of Experimental Psychology: Human Perception \& Performance, 20, 317-329.

Hawley, K. J., Johnston, W. A., \& FarnhaM, J. M. (1994). Novel popout with nonsense strings: Effects of predictability of string length and spatial location. Perception \& Psychophysics, 55, 261-268.

Johnston, W. A., \& HaWley, K. J. (1994). Perceptual inhibition of expected inputs: The key that opens closed minds. Psychonomic Bulletin \& Review, 1, 56-72.

Johnston, W. A., Hawley, K. J., \& Farnham, J. M. (1993). Novel popout: Empirical boundaries and tentative theory. Journal of Experimental Psychology: Human Perception \& Performance, 19, 140-153.

Johnston, W. A., Hawley, K. J., Plewe, S. H., Elliott, J. M. G., \& DEWITT, M. J. (1990). Attention capture by novel stimuli. Journal of Experimental Psychology: General, 119, 397-411.

Johnston, W. A., \& Schwarting, I. S. (1996). Reassessing the evidence for novel popout. Journal of Experimental Psychology: General, 125, 208-212.

Johnston, W. A., \& SChwarting, I. S. (1997). Novel popout: An enigma for conventional theories of attention. Journal of Experimental Psychology: Human Perception \& Performance, 23, 622-631.

JONIDES, J., \& YANTIS, S. (1988). Uniqueness of abrupt visual onset in capturing attention. Perception \& Psychophysics, 43, 346-354.

KuČERA, J., \& FRANCIS, W. N. (1967). Computational analysis of presentday American English. Providence, RI: Brown University Press.

Mandler, G., NaKamura, Y., \& VAN ZANDT, B. J. S. (1987). Nonspecific effects of exposure on stimuli that cannot be recognized. Journal of Experimental Psychology: Learning, Memory, \& Cognition, 13, 646-648.

SCHNEIDER, W. (1988). Micro Experimental Laboratory: An integrated system for IBM PC compatibles. Behavior Research Methods, Instruments, \& Computers, 20, 206-217.

SCHNEIDER, W. (1990). MEL user's guide: Computer techniques for real time experimentation. Pittsburgh: Psychology Software Tools.

Theeuwes, J. (1991). Cross-dimensional perceptual selectivity. Perception \& Psychophysics, 50, 184-193.

Theeuwes, J. (1992). Perceptual selectivity for color and form. Perception \& Psychophysics, 51, 599-606.

TheEuwes, J., \& BuRger, R. (1998). Attentional control during visual search: The effect of irrelevant singletons. Journal of Experimental Psychology: Human Perception \& Performance, 24, 1342-1353.

YANTIS, S., \& JoNIDES, J. (1984). Abrupt visual onsets and selective attention: Evidence from visual search. Journal of Experimental Psychology: Human Perception \& Performance, 10, 601-620.

\section{NOTE}

1. Christie and Klein (1995) manipulated absolute familiarity (e.g., words vs. nonwords), and not the relative familiarity of word stimuli in the experimental context (e.g., Johnston et al., 1993; Johnston et al., 1990).

(Manuscript received September 8, 1997; revision accepted for publication November 9,1999 .) 